\title{
História das mulheres, da academia para os almoços de domingo
}

\author{
Minha história das mulheres.
}

PERROT, Michelle.

São Paulo: Contexto, 2007. 191 p. (Tradução de Angela M. S. Côrrea do orig inal Mon histo ire des femmes. Paris: Éditions du Seuil/France Culture, 2006.)

Hoje a História das mulheres é uma área acadêmic a consolidada. Cursos regulares, simpósios concomidos, produção intelec tual farta e public ações especializadas a cessíveis em bibliotec a se livra ria sc orrob oram essa a firmação.

O caminho até sua legitimação, embora não tenha sido fácil, parece irreversível. Olhar para trás só valoriza a conquista: no século XVIII, pensa dores disc utia $m$ se as mulheres eram seres huma nos como os homens ou se se a proximavam ma is d os a nima is irrac iona is. Ela s esperaram a té o final do XIX para ver reconhecido seu direito à educação e muito mais tempo para poder ingressar nas universidades. No século XX, fic ou mais claro que as mulheres têm uma história, e que podem conscientemente tentar tomá-la nas mãos, com seus movimentos e reivindicações. Também se concluiu, finalmente, que a história dasmulheres podia serescrita. Eque ela ta mbém ilumina e sofistica a história geral. Daí para o desenvolvimento dos estudos de gênero, considerando o caráter social e histórico das representações de feminino e masculino, foi rela tiva mente rápido.

A hora, agora, é fazer com que um públic o ma is a mplo tenha acesso às descobertas dos pesquisadores. A História precisa sair das universidades e ganhar as ruas. A história das mulheres deve serdiscutida nos sa lões de beleza, nos a lmoços de família, nas mesas de bar, nos ambientes de trabalho; deve estar presente na elaboração de políticas públicas, nas escolas, nas TVs e nas rádios.

Ma is uma vez os franceses saíram na frente. Acostumados que estão à figura do "historiador públic o" (a quele que tem um compromisso social, assume posições políticas, vai à mídia divulgar suas idéias, procura dialogar com um público ma is a mplo), tiveram a feliz idéia de levara história das mulheres aos ouvintes de rádio. Michelle Perrot, uma das pesquisadoras ma is importantes do tema, foi convidada pela France Culture a participar de uma série radiofônica que, em 25 programas (de 28 de fevereiro a 10 de abril de 2005), sintetizou, "traduziu" e divulgou para um público de não-especialista so conteúdo de ma is de 30 anos de pesquisas e reflexões acadêmicas sobre as mulheres. A iniciativa, levada a cabo na voz clara e entusiasmada da própria Perrot, alcançou uma audiência extraordinária. Para perpetuar e ampliar tal sucesso, a série foi transforma da em livro em ma rço de 2006. A obra ganhou nas páginas da imprensa francesa elogios como "texto apaixonante", "resumo inteligente da história das mulheres", "sensível e pessoal como uma boa conversa a o pé do fogo". No Brasil, a Editora Contexto (a mesma de História das mulheres no Brasil e História da cidadania) rapidamente providenciou a edição em português: Minha história das mulheres.

Embora a autora (mundia Imente respeita da e com muitos admiradores no Brasil) já tenha vá rios livros public a dos em nossa língua, não há nisco em a fimarque nenhum outro é tão acessível e instigante quanto esse, justamente por ter nascido de uma vontade de falara muita gente e com coragem de assumir posições ta mbém a respeito de assuntos da a tualidade.

Em Minha história das mulheres, Michelle Perrot toma a liberdade de daruma visã o pessoal de um tema sobre o qual se debruça há muitos anos. Ao mesmo tempo, mostra como essa história é de todasasmulheres; de todosnós, na verdade, já que fala também da relação com os homens, da sexualidade, da família, das representações de masculino e feminino, das classes socia is, do poder, da sociedade. Destacar as mulheres é uma forma de reforçar a idéia de que elas têm uma história, da qual são ta mbém sujeito a tivo. Significa também, sem nenhuma contradição com a seriedade cobrada dos pesquisadores acadêmicos, engajar-se como militante no projeto de emancipação das mulheres da forma como faz Mic helle Perrot. 0 eixo central da história escrita à la Perrot é o processo da crescente visibilidade das mulheres em seus combates e suas conquistas nos espaços público e privado. 
Para na rá-lo, a autora elege cortes temátic os que constituem os cinco capítulos do livro.

O primeiro capítulo tra ta do significado de escrever a história das mulheres, quando as próprias mulheres, incorporando a idéia de que sua existência é priva da e sem importância, foram responsáveis pela chamada autodestruição da memória feminina, o que, somada aos silêncios impostos e às imagens distorcidas do feminino, criou toda sorte de dific ulda des a os historia dores interessados no tema. Ao narrar a trajetória da legitimação acadêmica dos estudos sobre as mulheres nas universidades francesas, a autora lança mão de sua própria experiência, já que, como uma daspioneiras na área, foi testemunha oculare privilegiada de todo esse processo que chamou de "uma revolução intelectual de primeira ordem". Otimista, fala dos avanços: o questionamento da avalanche de discursose de imagens sobre as mulheres (muita s vezes um olhar masc ulino enviesa do), a ruptura dos silênciose o nascimento desse campo específic o de pesquisa. Também trata dasfontese de sua a cessibilidade. Descobrimos, com uma certa ponta de inveja, como os franceses têm investido recentemente em aquisições de documentos, a rquivos, publicações, bibliotecas e sites sobre a história das mulheres.

No segundo capítulo, o tema é o corpo. Começando pelas "idades da vida", mostra a historicidade da questão da longevidade das mulheres (tema em que "o biológico se dissolve no existencial"), estudando desde as representações em torno do nascimento de meninos e meninas (e a prática do infanticídio de bebezinhas, existente até hoje em certos lugares) até a velhice das mulheres, passando pela educação diferenciada por sexo, a menstruação e a menopausa. Ba sea da em fontes diversas, que vão de dados demográficos à literatura de ficção, discorre sobre casamento, sexo, maternidade e controle da natalidade. Motivada talvez pela recente polêmica que dividiu opiniões na França entre favoráveis e contrasa que ga rotas muçulma nas usem véu nas escolas públicas, Michelle Perrot dedica muitas páginas às representações que envolvem os cabelos das mulherese à "longa história do véu", tra tando-os como evidências nítidas dos códigos socia is envolvidos nas construções do feminino. Finaliza o capítulo com um panorama da submissão do corpo feminino; as repressões de tod o tip o, estup ros coletivose "instituc iona liza dos", prostituição, a ssédio sexual, violência doméstica.

A alma vem no terceiro capítulo - a religião, a cultura, a educação, o a cesso ao saber, a criação -, trazendo à tona hereges, santas e feitic eiras, leitoras e escritoras, artistas, sábias e criadoras. As dificuldades, o desenvolvimento de práticas femininas e as conquistas contemporâneas nos campos da "alma" podem ser vislumbrados por meio da abordagem sensível de Mic helle Perrot muito bem casada com o volume imenso de informações devidamente embasadas que seu livro disponibiliza.

Em O trabalho das mulheres, conhecemos o cotidiano das camponesas, os afazeres e protestos das donas-de-casa, as condições de vida das criadas e empregadas domésticas, as dificuldades e conquistas das operárias, a trajetória das professoras, o desempenho das vendedoras, a performance das a trizes. Segundo Perrot, as mulheres sempre traba lharam, mas era um "trabalho invisível", nã o valorizado, não remunerado. 0 acesso a o exercício de atividades reconhecidas e profissões remuneradas é historic amente recente, estando o trabalho das mulheres ainda longe de igualar-se ao dos homens em temos de valorização social e ganhos sala ria is. Além disso, conquistas femininas no espaço público, embora sejam um avanço evidente, podem revelar a lgumas contradições como, por exemplo, a conhecida dupla jomada de tra balho e a a tual estig matização dos a fazeres domésticos.

Fina Imente, no quinto c a pítulo, Mulheres na cidade, migramos com fugitivas e exiladas ou esperançosas trabalhadoras e militantes. Viajamos com missionárias, cientistas e a ventureiras. Atra vessa mos fronteiras da História, redefinindo cronologias em função da especificida de da experiência históric a feminina. Em seguida, invadimos a "Cidade proibida" por meio de todas as formas de ação coletiva adota das pelas mulheres na luta pordireitos civis, polític os, socia is, com destaque para o a cesso à contracepção, a liberdade sexual, o combate à violência de gênero de todo tipo, incluindo as a bomináveis mutilações genita is a inda praticadas por grup os funda menta listas.

Ao perguntar E agora?, Michelle Perrot convida a pensar a respeito da questão que perpassa tod o o livro: "Como evoluiu a diferença dos sexos? Como se modificaram as partilhas entre os homens e as mulheres, suas id entidades e sua hierarquia?" (p. 165). Ressalta uma vez ma is a repressão sofrida pelas mulheres, mas lembra que sua história não é feita só de violências e submissões: "o status de vítima não resume o papel das mulheres na história, que sabem resistir, existir, construir seus poderes" (p. 166). Mic helle 
Perrot rec usa exp lic ita mente qua lquer perspec tiva maniqueísta da relação dos sexose defende que esc rever a história das mulheres "não é um meio de reparação, mas desejo de compreensã 0 , de inteligibilidade global" (p. 166).

Apesar de não se deter no assunto, menciona a contribuição de pesquisas sobre a história das mulheres fora do campo da História Modema e Contemporânea, ricos acréscimos feitos por medievalistas e especialistas em Antigüida de e Pré-História. Ta mbém faz referências a outros espaços, para além da Europa e dos Estados Unidos, constatando que a História das mulheres e das relações de gênero se desenvolveu muito "no Extremo Oriente, pelo menosna Índia e no J a pão, e na América Latina, partic ula mente no Brasil (com centros de estudos muito a tivos em Campinas, Rio e Floria nópolis), e mesmo na África, onde não é fácil escapar de representações etnológicas um tanto engessadas" (p. 167). Conclui fazendo um breve balanço da condição feminina nos dias hoje e estimulando novas pesquisas naquela que é também uma "história a se fazer".

Minha história das mulheres faz va ler o dito toda História é História Contemporânea: tem um compromisso com o presente, interroga o passa do tomando como referência questões que fazem parte de nossa vida. Ecumpre a promessa de divulgara história das mulheres: procura falar a pessoas de fora da academia, permitindo-lhes enxergarpassado e presente com muita cla reza, por meio de exemplos concretos, descrições detalhadas, paralelos com situações contemporâneas, a nálise s em linguagem a cessível e comentá rios corajosos. Daí pa ra esta história virarassunto nos a Imoços de fa mília talvez nã o falte muito. Com Minha história das mulheres um passo foi dado.

\section{Carla Bassanezi Pinsky}

Historia dora 